\title{
Transcriptome Dynamics of Floral Organs Approaching Blooming in the Flowering Cherry (Cerasus $\times$ yedoensis) Cultivar 'Somei-Yoshino'
}

$1 \quad$ Kenta Shirasawa $^{1^{*}}$, Tomoya Esumi ${ }^{2}$, Akihiro Itai $^{3}$, Sachiko Isobe $^{1}$

2 Laboratory of Plant Genetics and Genomics, Department of Frontier Research and Development,

3 Kazusa DNA Research Institute, Kisarazu, Chiba 292-0818, Japan

$4 \quad{ }^{2}$ Laboratory of Pomology \& Viticulture, Department of Agricultural and Life Sciences, Shimane

5 University, Matsue, Shimane 690-8504, Japan

$6 \quad{ }^{3}$ Laboratory of Plant Resource Science, Department of Agricultural and Life Science, Kyoto

7 Prefectural University, Sakyo, Kyoto 606-8522, Japan

8 * Correspondence:

9 Kenta Shirasawa

10 shirasaw@kazusa.or.jp

11 Word count: 2796

12 Number of figures: 3

13 Number of tables: 1

14 Number of supplementary figures: 4

15 Number of supplementary tables: 3

16 Keywords: cherry blossom forecast, flowering cherry, RNA sequencing, time-course analysis, 17 transcriptomics

\section{Abstract}

19 To gain insights into the genetic mechanisms underlying blooming and petal movement in flowering cherry (Cerasus $\times$ yedoensis), we performed time-course RNA-seq analysis of the floral buds and open-flowers of the most popular flowering cherry cultivar, 'Somei-Yoshino'. Independent biological duplicate samples of floral buds and open-flowers were collected from 'Somei-Yoshino' trees grown at three different locations in Japan. RNA-seq reads obtained from floral bud and open-flower samples collected in the current study (in 2019) and in a previous study (in 2017) were aligned against the genome sequence of 'Somei-Yoshino' to quantify gene transcript levels. Clustering analysis of RNA-seq reads revealed dynamic changes in the transcriptome, with genes in seven modules predominantly expressed at specific time points, ranging from 5 weeks before flowering to 2 weeks after flowering. Based on the identified gene modules and Gene Ontology (GO) terms enriched at different floral stages, we speculate that the genetic mechanisms underlying petal movement and flower opening in cherry involve the processes of development, cell wall organization, reproduction, and metabolism, which are executed by genes encoding transcription factors, phytohormones, transporters, and polysaccharide metabolic enzymes. Furthermore, we propose a method for cherry bloom forecasting, based on gene expression levels at different time points before flowering as RNA markers. 
Flowering cherry, also known as sakura, typically blooms in the spring and is valued as a popular ornamental flower across the world. 'Somei-Yoshino' (Cerasus $\times$ yedoensis), which is presumed to be an interspecific hybrid between C. spachiana and C. speciosa (Takenaka, 1963; Innan et al., 1995; Nakamura et al., 2015), is the most popular cultivar of flowering cherry in Japan. Given its genomic heterozygosity and self-incompatibility, 'Somei-Yoshino' is propagated by grafting (Iketani et al., 2007). Because of its clonal nature, 'Somei-Yoshino' trees planted within a specific location bloom at the same time; however, across the Japanese archipelago, the blooming front progresses from south to north because of differences in environmental conditions. Since the blooming date is important for the tourism industry in the spring season, forecasting methods based on cumulative temperature have been developed to predict the flowering date of cherry blossoms (Aono and Murakami, 2017).

Flowering involves two main processes: floral bud initiation and flower opening. The molecular mechanisms of floral bud initiation have been well studied in Arabidopsis thaliana and rice (Oryza sativa) as flowering models of long- and short-day plants, respectively, revealing that FLOWERING LOCUS T $(F T)$ is the key gene involved in floral bud differentiation (Izawa et al., 2003). This mechanism is widely conserved across plant species (Higuchi, 2018). In woody plants, following floral bud initiation, buds enter a period of dormancy, which is followed by dormancy release and bud break. In the Rosaceae family members, DORMANCY-ASSOCIATED MADS-box (DAM) genes have been reported to regulate bud dormancy (Yamane, 2014). However, while the physiological aspect of the flower opening mechanism has been thoroughly investigated, only a few studies have been conducted to explore the genetic basis of this mechanism (van Doorn and Van Meeteren, 2003).

The genome sequence of 'Somei-Yoshino' has been determined at the chromosome level, and genes involved in the regulation of dormancy and flowering time have been identified in this cultivar through time-course transcriptome analysis (Shirasawa et al., 2019). Since expression levels of key genes transmit the environmental conditions, such as day-length and temperature, to biological processes such as blooming, the identification of these genes might help predict the blooming date in flowering cherry. Because the transcriptome is affected by environmental conditions (e.g., changes in weather and habitat), biological replications of flowering cherry trees over multiple years and locations would be required for the accurate identification of genes affecting the blooming date.

In this study, we aimed to identify genes uniquely expressed before and after flowering, and to obtain insights into the molecular mechanisms underlying blooming in flowering cherry. We collected floral buds and open-flowers from 'Somei-Yoshino' trees planted at three locations in Japan (Chiba, Kyoto, and Shimane) in 2019, and analyzed their transcriptome using the RNA sequencing (RNA-seq) technology. The time-course transcriptome data generated in the current study and in our previous study (Shirasawa et al., 2019) was used to characterize gene expression patterns in 'Somei-Yoshino' floral buds, some of which could be used to forecast the blooming time and to gain insights into the molecular mechanisms controlling blooming in flowering cherry.

\section{Materials and Methods}

\subsection{Plant Materials}

Seven clonal trees of 'Somei-Yoshino' were used in this study. One tree was planted at the Kazusa DNA Research Institute (KDRI; Kisarazu, Chiba, Japan), and three trees each were planted at two different locations: Shimane University (SU; Matsue, Shimane, Japan; trees 1-3) and Kyoto Prefectural University (KPU; Sakyo, Kyoto, Japan; trees A-C). Floral buds and open-flowers were 
collected in 2019 over an extended time period, ranging from 36 days before flowering (DBF) to 11 days after flowering (DAF) (Figure 1), corresponding to 6 weeks before flowering (WBF) to 2 weeks after flowering (WAF) (Supplementary Table S1).

\subsection{RNA-seq Analysis}

Library preparation and sequencing analysis were performed as described in Shirasawa et al. (2019). In short, total RNA was extracted from the buds and open-flowers with RNeasy Plant Min Kit (Qiagen, Hilden, Germany). The RNA was treated with RNase-free DNase (Promega, Madison, WI, USA) and used for library construction with TruSeq Stranded mRNA Library Prep Kit (Illumina, San Diego, CA, USA). The library was sequenced on NextSeq 500 (Illumina) in paired-end, 76 bp mode.

\subsection{RNA Sequence Data Processing}

RNA-seq data was analyzed as described previously (Shirasawa et al., 2019). High-quality reads were selected by trimming the adapter sequences using fastx_clipper (parameter, -a AGATCGGAAGAGC) in the FASTX-Toolkit v.0.0.13 (http://hannonlab.cshl.edu/fastx_toolkit), and by deleting low-quality bases using PRINSEQ v.0.20.4 (Schmieder and Edwards, 2011). Highquality reads were mapped to the CYE_r3.1_pseudomolecule sequence (Shirasawa et al., 2019) using HISAT2 v.2.1.0 (Kim et al., 2015), and reads mapped to each gene model were quantified and normalized to determine the number of fragments per kilobase of transcript per million mapped reads (FPKM) using StringTie v.1.3.5 (Pertea et al., 2015) and Ballgown v.2.14.1 (Frazee et al., 2015), as described previously (Pertea et al., 2016). Genes showing a variance of $\geq 1$ in expression levels among samples were used for further analysis.

\subsection{Gene Ontology (GO) Enrichment Analysis of Gene Modules}

The weighted gene correlation network analysis (WGCNA; v.1.66) package of R (Langfelder and Horvath, 2008) was used for module detection. The floral bud and open-flower samples were grouped in accordance with gene expression levels using the hierarchical clustering algorithm. Then, highly co-expressed gene clusters were constructed as modules. Genes included in the modules were functionally annotated by performing a BLAST sequence similarity search (Altschul et al., 1997) against the non-redundant (nr) protein database. GO terms were assigned to genes, and the statistical analysis of the GO term enrichment in each module was performed using Fisher's exact test implemented in OmicsBox (BioBam, Valencia, Spain). GO maps were drawn with QuickGO (Huntley et al., 2009).

\section{$3 \quad$ Results}

\subsection{RNA-seq Analysis and Quantification of Gene Expression Levels}

A total of 94 samples were collected from flowering cherry trees at KDRI, SU, and KPU over a period of 47 days (i.e., 36 days before anthesis to 11 days post-anthesis) in 2019 (Figure 1, Supplementary Table S1). Total RNA was extracted from the samples and subjected to RNA-seq analysis, which returned approximately 4.7 million reads per sample. Nucleotide sequence data of the RNA-seq were deposited in the DDBJ Sequence Read Archive (accession numbers DRA012801, DRA012802, and DRA012803). We also utilized the RNA-seq data generated previously (Shirasawa et al. 2019; DRA accession number DRA008100) from samples collected at KDRI in 2017. The RNA-seq reads from both datasets were mapped on to the genome sequence of 'Somei-Yoshino' (Shirasawa et al., 2019), and expression levels were normalized in all samples based on the total 
reads to obtain FPKM values for each gene across the samples. Of the 95,076 genes predicted in the 'Somei-Yoshino' genome (Shirasawa et al., 2019), a total of 29,712 genes (31.3\%) were expressed across the different samples, with a variance of $\geq 1$.

\section{$123 \quad 3.2 \quad$ Gene Module Detection}

124 On the basis of the expression patterns of 29,712 genes, one floral bud sample collected at 27 days before anthesis from the KDRI location was identified as an outlier and therefore was excluded from further analyses (Supplementary Figure S1). The remaining 93 samples were roughly clustered into 53 highly co-expressed gene modules, based on the expression patterns of 29,712 genes (Supplementary Figure S2), which were further classed into four groups, based on eigengenes (Supplementary Figure S3). Genes in 7 out of 53 modules were prominently expressed at specific days before or after anthesis (Figure 2): dark-red module (110 genes expressed at 4-5 weeks before flowering [WBF]), tan module (267 genes, $4 \mathrm{WBF}$ ), pink module (332 genes, $3 \mathrm{WBF}$ ), royal blue module (127 genes, 2-3 WBF), midnight blue module (176 genes, 1-2 WBF), black module (457 genes, at flowering days), and sky-blue module (72 genes, 1-2 weeks after flowering [WAF]).

\section{$134 \quad 3.3 \quad$ GO Enrichment Analysis}

135 To identify the GO terms enriched in each module, the ratios of GO terms in each gene module were compared with those of the remaining gene set (Table 1, Figure 2, Supplementary Table S2, Supplementary Figure S4).

138 At 4-5 WBF (dark-red module), the following GO terms were enriched: biological process (BP) category: 'developmental process' related GO terms including 'aging', 'embryo development', 'developmental maturation', 'developmental process', and 'anatomical structure development'; molecular function (MF) category: 'oxidoreductase activity'; and cellular component (CC) category: 'plasma membrane' and 'cell periphery'.

At $4 \mathrm{WBF}$ (tan module), GO terms enriched in the BP category were not only related to 'developmental process' ('anatomical structure formation involved in morphogenesis' and 'anatomical structure development') but also 'cellular process' ('sulfur compound metabolic process', 'biosynthetic process', 'developmental process', and 'cell wall organization or biogenesis'). GO terms enriched in the MF category included 'DNA binding', 'DNA-binding transcription factor activity', 'catalytic activity', 'oxidoreductase activity', 'transferase activity, transferring acyl groups', 'hydrolase activity, acting on glycosyl bonds', 'lyase activity', and 'transcription regulator activity', while those enriched in the CC category included 'extracellular region'.

At 3 WBF (pink module), the following GO terms were enriched: BP category: 'lipid metabolic process', 'autophagy', 'small molecule metabolic process', and 'process utilizing autophagic mechanism'; MF category: 'catalytic activity', 'transporter activity', 'lipid binding', 'oxidoreductase activity', 'transferase activity, transferring acyl groups', and 'transmembrane transporter activity'; and CC category: 'extracellular region', 'extracellular space', 'vacuole', 'plasma membrane', 'membrane', and 'cell periphery'.

At 2-3 WBF (royal blue module), the following GO terms were enriched: BP category: 'mitotic cell cycle', 'carbohydrate metabolic process', 'catabolic process', 'secondary metabolic process', 'cell division', and 'cell wall organization or biogenesis'; and CC category: 'extracellular region', 'cell wall', 'Golgi apparatus', 'plasma membrane', 'endomembrane system', 'membrane', 'external encapsulating structure', 'cell periphery', and 'cellular anatomical entity'. 
At 1-2 WBF (midnight blue module), the enriched GO terms included 'pollen development' and 'gametophyte development' (BP category); and 'transporter activity' and 'transmembrane transporter activity' (MF category).

165 At the flowering stage (black module), the following GO terms were enriched: BP category:

166 'carbohydrate metabolic process', 'cytoskeleton organization', 'catabolic process', and 'cell wall organization or biogenesis'; MF category: 'lipid binding', 'lyase activity', 'enzyme regulator activity', and 'molecular function regulator'; and CC category: 'extracellular region' and 'extracellular space'.

170 At 1-2 WAF (sky-blue module), the following GO terms were enriched: BP category: 'carbohydrate metabolic process', 'cellular protein modification process', 'response to stress', 'cell communication', 'signal transduction', 'metabolic process', 'catabolic process', 'signaling', 'protein modification process', 'macromolecule modification', 'primary metabolic process', 'regulation of biological process', 'regulation of cellular process', 'response to stimulus', 'cellular response to stimulus', 'biological regulation', 'cell wall organization or biogenesis', and 'organic substance metabolic process'; MF category: 'lipid binding', 'hydrolase activity, acting on glycosyl bonds', 'enzyme regulator activity', and 'molecular function regulator'; and CC category: 'nucleus'. Thus, the GO terms enriched at this stage were drastically different from those enriched at the other stages.

\subsection{Genetic Mechanisms Underlying Blooming in Flowering Cherry}

To gain insights into the genetic mechanisms regulating blooming in flowering cherry, we focused on genes categorized in four functional categories (Figure 2, Supplementary Table S3): 1) transcription factor genes; 2) phytohormone-related genes; 3) transporter and aquaporin genes; and 4) cell wallrelated genes.

\subsubsection{Transcription factor genes}

185 Genes encoding three types of transcription factors that trigger blooming were predominant during

186 the flowering period. The $M Y B$ transcription factor genes were overrepresented from 4 to $3 \mathrm{WBF}$, 187 while the ethylene-responsive transcription factor $(E R F)$ genes and $N A C$ transcription factor genes 188 were expressed at 4 and $3 \mathrm{WBF}$, respectively.

\subsubsection{Phytohormone-related genes}

190 Genes involved in biosynthesis and signal transduction pathways of gibberellin, ethylene, and cytokinin were enriched at 3-5 WBF, 3-4 WBF, and $3 \mathrm{WBF}$, respectively. Auxin-related genes were, on the other hand, expressed at $1 \mathrm{WBF}$ and at the flowering days.

\section{$193 \quad$ 3.4.3 Transporter and aquaporin genes}

194 Genes encoding sugar and inorganic transporters and aquaporins that affect the turgor and osmotic pressure of cells and vacuoles were constitutively expressed from $5 \mathrm{WBF}$ to the day for flowering. Among these, genes encoding 10 types of transporters (ABC transporter $\mathrm{G}$ family members, bidirectional sugar transporters, cationic amino acid transporters, lysine histidine transporters, organic cation/carnitine transporters, phosphate transporters, potassium transporters, UDP-galactose transporters, vacuolar amino acid transporters, and zinc transporters) were overrepresented at $3 \mathrm{WBF}$. Aquaporin genes were overrepresented at 1-2 WAF. 


\subsubsection{Cell wall-related genes}

202 Cell wall organization followed by cell expansions actuate petal movement, leading to flower opening. Genes encoding polysaccharide biosynthesis enzymes including UDP-glycosyltransferases and cellulose synthases were expressed from $5 \mathrm{WBF}$ to the day for flowering. Genes encoding fasciclin-like arabinogalactan proteins were mainly expressed at the initial stage of the flowering period, while those encoding arabinogalactan peptides were expressed at the flowering days. Pectinesterase genes were overrepresented at the flowering days.

\section{Discussion}

209 Time-course RNA-seq analysis revealed the dynamics of the transcriptome of floral buds and flowers of the flowering cherry cultivar 'Somei-Yoshino'. Subsequent WGCNA of the RNA-seq data indicated that 1,541 genes belonging to seven modules were involved in blooming at stages from 4-5 WBF to 1-2 WAF (Figure 2). In accordance with the functional annotations of these genes, those involved in floral bud and open-flower development as well as blooming were identified in flowering cherry (Figure 3). Floral bud development potentially occurs from 4-5 WBF, with the gibberellinmediated activation of genes controlling sugar and polysaccharide metabolism. Subsequently, at 3-4 $\mathrm{WBF}$, ethylene and cytokinin likely accelerate the expression of $M Y B, E R F$, and $N A C$ transcription factor genes, resulting in the initiation of cell wall organization and cell division (Nakano et al., 2015). Some $M Y B$ and $N A C$ genes are also involved in gametophyte or ovule integument development (Kunieda et al., 2008; Renak et al., 2012). According to the observations in sweet cherry (Prunus avium), the 3-4 WBF timepoint corresponds to the formation of tetrads or microspores after meiosis in the pollen (Fadon et al., 2019). At this stage, amino acid metabolism is also upregulated. Metabolome analysis of the flower buds of Japanese apricot (Prunus mume) revealed significant changes in the abundance of several amino acids before the bud break stage (Zhuang et al., 2015). Amino acids play important roles in bud break. At 1-2 WBF, the reproduction process, together with metabolism, is likely activated. Auxin-related genes were also activated at this stage in this current study. On the flowering day, we speculate that the auxin signal alters pectinesterase gene expression to initiate cell wall remodeling, leading to rapid petal enlargement and movement, which is the most dynamic movement in flowering plants (Habu and Tao, 2014; Nakano et al., 2015). The high-level expression of aquaporin genes, which encode water channel proteins localized to the plasma membrane or tonoplast membranes, on the day of flowering might facilitate the water flux into the petals to allow smooth petal movement (Azad et al., 2013). The relationship between auxin signaling and pectinesterase gene expression has been demonstrated in the ripening process of strawberry fruit (Castillejo et al., 2004). Similar hormonal regulations might be conserved in the Rosaceae species. The role of the auxin signal in the dynamic movement of petals during flower opening needs further investigation. After blooming, genes involved in the stimulus response and cell-to-cell communication are expressed the flower, especially in the pistil and ovary, which might reflect the pollination and fertilization process, even though 'Somei-Yoshino' is selfincompatible. Similar transcriptome profiles were observed in other Prunus species (Habu and Tao, 2014; Gómez et al., 2019; Iqbal et al., 2021).

Because the flowering time of 'Somei-Yoshino' is important for the tourism industry in Japan, methods for predicting the flowering date of this cultivar have been developed in accordance with the cumulative temperature before flower opening (Aono and Murakami, 2017). Gene expression analysis could upgrade the current forecasting model, for which genes expressed on specific days before flowering could be employed as diagnostic markers. However, practical RNA quantification methods, such as real-time quantitative PCR and the next-generation sequencing (NGS)-based RNAseq, are time-consuming and labor-intensive. Since diagnostic markers can be detected easily within 
a short time, easy-to-use target-RNA qualifying methods are required to predict the flowering time in

'Somei-Yoshino', based on gene expression data.

249 Comparative time-course transcriptome analysis would enable the selection of high-confidence

250 diagnostic markers for various purposes. For example, time-course transcriptome analysis can be

251 applied to floral buds of vegetable and fruit crops and cut flowers. Moreover, this comparative

252

253

254 analysis is not only limited to the selection of markers for forecasting flowering time but is also applicable to the prediction of disease, fertilization, and harvest time in the field. Indeed, transcriptome profiling has been employed to monitor nutritional responses and adaptation in rice (Takehisa and Sato, 2021).

256

Overall, this study provides insights into the genetic mechanisms controlling petal movement and

257

258

259 blooming in cherry. Further studies are required to connect the genetic insights with the physiological mechanisms (van Doorn and Van Meeteren, 2003). Once the connection or relationship is validated, the transcriptome-based prediction would serve as a powerful tool for monitoring the plant phenotype under controlled cultivation conditions as well as in the field. For example, genome-based prediction has been used to predict progeny phenotypes in breeding programs. The transcriptome- and genomebased predictions would promise high-confidence forecasting plant traits in the near and distant future, respectively.

\section{Conflict of Interest}

265 The authors declare that the research was conducted in the absence of any commercial or financial 266 relationships that could be construed as a potential conflict of interest.

\section{Author Contributions}

$268 \mathrm{KS}, \mathrm{TE}$, and AI conceived this study and collected the samples; KS and SI performed experiments 269 and collected data; KS, TE, and AI analyzed and interpreted the data; KS wrote the manuscript with

270 contributions from TE; and all authors read and approved the final manuscript.

\section{$271 \quad 7 \quad$ Funding}

272 This work was supported by the Kazusa DNA Research Institute Foundation.

\section{Acknowledgments}

274 We thank Y. Kishida, C. Minami, S. Sasamoto, H. Tsuruoka, and A. Watanabe (Kazusa DNA

275 Research Institute) for providing technical assistance.

\section{References}

277 Altschul, S.F., Madden, T.L., Schaffer, A.A., Zhang, J., Zhang, Z., Miller, W., and Lipman, D.J. 278 (1997). Gapped BLAST and PSI-BLAST: a new generation of protein database search programs. 279 Nucleic Acids Res 25, 3389-3402.

280 Aono, Y., and Murakami, N. (2017). A simplified method to estimate cherry blossom phenology

281 considering temperature during endodormancy process. Climate in Biosphere 17, 25-33. 
282

283

284

285

286

287

288

289

290

291

292

293

294

295

296

297

298

299

300

301

302

303

304

305

306

307

308

309

310

311

312

313

314

315

316

317

318

Azad, A.K., Hanawa, R., Ishikawa, T., Sawa, Y., and Shibata, H. (2013). Expression profiles of aquaporin homologues and petal movement during petal development in Tulipa gesneriana. Physiol Plant 148, 397-407.

Castillejo, C., De La Fuente, J.I., Iannetta, P., Botella, M.A., and Valpuesta, V. (2004). Pectin esterase gene family in strawberry fruit: study of FaPE1, a ripening-specific isoform. $J \operatorname{Exp}$ Bot 55, 909-918.

Fadon, E., Herrero, M., and Rodrigo, J. (2019). Anther and pollen development in sweet cherry (Prunus avium L.) in relation to winter dormancy. Protoplasma 256, 733-744.

Frazee, A.C., Pertea, G., Jaffe, A.E., Langmead, B., Salzberg, S.L., and Leek, J.T. (2015). Ballgown bridges the gap between transcriptome assembly and expression analysis. Nat Biotechnol 33, 243 246.

Gómez, E.M., Buti, M., Sargent, D.J., Dicenta, F., and Ortega, E. (2019). Transcriptomic analysis of pollen-pistil interactions in almond (Prunus dulcis) identifies candidate genes for components of gametophytic self-incompatibility. Tree Genetics \& Genomes 15.

Habu, T., and Tao, R. (2014). Transcriptome Analysis of Self- and Cross-pollinated Pistils of Japanese Apricot (Prunus mume Sieb. et Zucc.). Journal of the Japanese Society for Horticultural Science 83, 95-107.

Higuchi, Y. (2018). Florigen and anti-florigen: flowering regulation in horticultural crops. Breed Sci $68,109-118$.

Huntley, R.P., Binns, D., Dimmer, E., Barrell, D., O'donovan, C., and Apweiler, R. (2009). QuickGO: a user tutorial for the web-based Gene Ontology browser. Database (Oxford) 2009, bap010.

Iketani, H., Ohta, S., Kawahara, T., Katsuki, T., Mase, N., Sato, Y., and Yamamoto, T. (2007). Analyses of Clonal Status in 'Somei-yoshino' and Confirmation of Genealogical Record in Other Cultivars of Prunus $\times$ yedoensis by Microsatellite Markers. Breeding Science 57, 1-6.

Innan, H., Terauchi, R., Miyashita, N.T., and Tsunewaki, K. (1995). DNA fingerprinting study on the intraspecific variation and the origin of Prunus yedoensis (Someiyoshino). Jpn J Genet 70, 185-196.

Iqbal, S., Pan, Z., Hayat, F., Bai, Y., Coulibaly, D., Ali, S., Ni, X., Shi, T., and Gao, Z. (2021). Comprehensive transcriptome profiling to identify genes involved in pistil abortion of Japanese apricot. Physiol Mol Biol Plants 27, 1191-1204.

Izawa, T., Takahashi, Y., and Yano, M. (2003). Comparative biology comes into bloom: genomic and genetic comparison of flowering pathways in rice and Arabidopsis. Current Opinion in Plant Biology 6, 113-120.

Kim, D., Langmead, B., and Salzberg, S.L. (2015). HISAT: a fast spliced aligner with low memory requirements. Nat Methods 12, 357-360.

Kunieda, T., Mitsuda, N., Ohme-Takagi, M., Takeda, S., Aida, M., Tasaka, M., Kondo, M., Nishimura, M., and Hara-Nishimura, I. (2008). NAC family proteins NARS1/NAC2 and 
NARS2/NAM in the outer integument regulate embryogenesis in Arabidopsis. Plant Cell 20, 26312642.

321 Langfelder, P., and Horvath, S. (2008). WGCNA: an R package for weighted correlation network analysis. BMC Bioinformatics 9, 559.

323 Nakamura, I., Takahashi, H., Ohta, S., Moriizumi, T., Hanashiro, Y., Sato, Y., and Mill, M. (2015).

324 Origin of Prunus x yedoenins 'Somei-yoshino' based on sequence analysis of PolAl gene. Adv Hort

325 Sci 29, 17-23.

326 Nakano, Y., Yamaguchi, M., Endo, H., Rejab, N.A., and Ohtani, M. (2015). NAC-MYB-based

327 transcriptional regulation of secondary cell wall biosynthesis in land plants. Front Plant Sci 6, 288.

328 Pertea, M., Kim, D., Pertea, G.M., Leek, J.T., and Salzberg, S.L. (2016). Transcript-level expression 329 analysis of RNA-seq experiments with HISAT, StringTie and Ballgown. Nat Protoc 11, 1650-1667.

330 Pertea, M., Pertea, G.M., Antonescu, C.M., Chang, T.C., Mendell, J.T., and Salzberg, S.L. (2015).

331 StringTie enables improved reconstruction of a transcriptome from RNA-seq reads. Nat Biotechnol

$33233,290-295$.

333 Renak, D., Dupl'akova, N., and Honys, D. (2012). Wide-scale screening of T-DNA lines for 334 transcription factor genes affecting male gametophyte development in Arabidopsis. Sex Plant Reprod $33525,39-60$.

336 Schmieder, R., and Edwards, R. (2011). Quality control and preprocessing of metagenomic datasets.

337 Bioinformatics 27, 863-864.

338 Shirasawa, K., Esumi, T., Hirakawa, H., Tanaka, H., Itai, A., Ghelfi, A., Nagasaki, H., and Isobe, S. 339 (2019). Phased genome sequence of an interspecific hybrid flowering cherry, 'Somei-Yoshino'

340 (Cerasus x yedoensis). DNA Res 26, 379-389.

341 Takehisa, H., and Sato, Y. (2021). Transcriptome-based approaches for clarification of nutritional 342 responses and improvement of crop production. Breed Sci 71, 76-88.

343 Takenaka, Y. (1963). The Origin of the Yoshino Cherry Tree. Journal of Heredity 54, 207-211.

344 Van Doorn, W.G., and Van Meeteren, U. (2003). Flower opening and closure: a review. J Exp Bot 345 54, 1801-1812.

346 Yamane, H. (2014). Regulation of Bud Dormancy and Bud Break in Japanese Apricot (Prunus mume 347 Siebold ㅅ^amp; Zucc.) and Peach [Prunus persica (L.) Batsch]: A Summary of Recent Studies.

348 Journal of the Japanese Society for Horticultural Science 83, 187-202.

349 Zhuang, W., Gao, Z., Wen, L., Huo, X., Cai, B., and Zhang, Z. (2015). Metabolic changes upon

350 flower bud break in Japanese apricot are enhanced by exogenous GA4. Hortic Res 2, 15046. 


\section{$352 \quad 10 \quad$ Figure Legends}

353 Figure 1 Floral buds and open-flowers of 'Somei-Yoshino'. The numbers in each picture indicate

354 days before (-) or after (+) the flowering day (0). Photos were taken at Kazusa DNA Research

355 Institute in 2021.

356 Figure 2 Expression patterns of genes categorized into seven modules. $X$-axis indicates the number 357 of days before (-) or after (+) the flowering day (0). Lines show moving averages of gene expression 358 (sliding window size $=8$, walking speed $=4$ ). Symbols indicate biological replicates: KDRI in 2017 359 (circle); KDRI in 2019 (triangle); SU1 in 2019 (plus); SU2 in 2019 (cross); SU3 in 2019 (diamond); 360 KPUA in 2019 (upside-down triangle); KPUB in 2019 (square cross); and KPUC in 2019 (star).

361 Figure 3 Genes enriched in the biological process (BP) category and involved in the flower opening 362 mechanism in 'Somei-Yoshino'. Upper panels show the time frame (from 5 weeks before flowering

$363[\mathrm{WBF}]$ to 2 weeks after flowering [WAF]) and the corresponding gene modules. Arrows indicate the 364 Gene Ontology (GO) terms enriched in the BP category (see Table 1). Boxes indicate the properties 365 of the genes highly expressed in the seven characterized modules (see Supplementary Table S3). 
Table 1 Gene Ontology (GO) terms enriched at the different flowering stages.

\begin{tabular}{|c|c|c|c|c|c|}
\hline Module & No. of genes & Stage $^{1}$ & Biological process (BP) & Molecular function (MF) & Cellular component $(\mathrm{CC})$ \\
\hline Dark-red & 110 & $4-5 \mathrm{WBF}$ & $\begin{array}{l}\text { 'developmental process' } \\
\text { related GO terms including } \\
\text { 'aging', 'embryo } \\
\text { development', } \\
\text { 'developmental } \\
\text { maturation', } \\
\text { 'developmental process', } \\
\text { and 'anatomical structure } \\
\text { development' }\end{array}$ & 'oxidoreductase activity' & $\begin{array}{l}\text { 'plasma membrane' and } \\
\text { 'cell periphery' }\end{array}$ \\
\hline Tan & 267 & $4 \mathrm{WBF}$ & $\begin{array}{l}\text { 'anatomical structure } \\
\text { formation involved in } \\
\text { morphogenesis', } \\
\text { 'anatomical structure } \\
\text { development', 'sulfur } \\
\text { compound metabolic } \\
\text { process', 'biosynthetic } \\
\text { process', 'developmental } \\
\text { process', and 'cell wall } \\
\text { organization or biogenesis' }\end{array}$ & $\begin{array}{l}\text { 'DNA binding', 'DNA- } \\
\text { binding transcription factor } \\
\text { activity', 'catalytic } \\
\text { activity', 'oxidoreductase } \\
\text { activity', 'transferase } \\
\text { activity, transferring acyl } \\
\text { groups', 'hydrolase } \\
\text { activity, acting on glycosyl } \\
\text { bonds', 'lyase activity', and } \\
\text { 'transcription regulator } \\
\text { activity' }\end{array}$ & 'extracellular region’ \\
\hline Pink & 332 & $3 \mathrm{WBF}$ & $\begin{array}{l}\text { 'lipid metabolic process', } \\
\text { 'autophagy', 'small } \\
\text { molecule metabolic } \\
\text { process', and 'process } \\
\text { utilizing autophagic } \\
\text { mechanism' }\end{array}$ & $\begin{array}{l}\text { 'catalytic activity', } \\
\text { 'transporter activity', 'lipid } \\
\text { binding', 'oxidoreductase } \\
\text { activity', 'transferase } \\
\text { activity, transferring acyl } \\
\text { groups', and } \\
\text { 'transmembrane transporter } \\
\text { activity' activity, }\end{array}$ & $\begin{array}{l}\text { 'extracellular region', } \\
\text { 'extracellular space', } \\
\text { 'vacuole', 'plasma } \\
\text { membrane', 'membrane', } \\
\text { and 'cell periphery' }\end{array}$ \\
\hline
\end{tabular}




\section{Transcriptome Dynamics in Cherry Flowers}

\begin{tabular}{|c|c|c|c|c|c|}
\hline Royal blue & 127 & $2-3 \mathrm{WBF}$ & $\begin{array}{l}\text { 'mitotic cell cycle', } \\
\text { 'carbohydrate metabolic } \\
\text { process', 'catabolic } \\
\text { process', 'secondary } \\
\text { metabolic process', 'cell } \\
\text { division', and 'cell wall } \\
\text { organization or biogenesis' }\end{array}$ & not detected & $\begin{array}{l}\text { 'extracellular region', 'cell } \\
\text { wall', 'Golgi apparatus', } \\
\text { 'plasma membrane', } \\
\text { 'endomembrane system', } \\
\text { 'membrane', 'external } \\
\text { encapsulating structure', } \\
\text { 'cell periphery', and } \\
\text { 'cellular anatomical entity' }\end{array}$ \\
\hline $\begin{array}{l}\text { Midnight } \\
\text { blue }\end{array}$ & 176 & $1-2 \mathrm{WBF}$ & $\begin{array}{l}\text { 'pollen development' and } \\
\text { 'gametophyte development' }\end{array}$ & $\begin{array}{l}\text { 'transporter activity' and } \\
\text { 'transmembrane transporter } \\
\text { activity' }\end{array}$ & not detected \\
\hline Black & 457 & $\begin{array}{l}\text { Flowering } \\
\text { day }\end{array}$ & $\begin{array}{l}\text { 'carbohydrate metabolic } \\
\text { process', 'cytoskeleton } \\
\text { organization', 'catabolic } \\
\text { process', and 'cell wall } \\
\text { organization or biogenesis' }\end{array}$ & $\begin{array}{l}\text { 'lipid binding', 'lyase } \\
\text { activity', 'enzyme regulator } \\
\text { activity', and 'molecular } \\
\text { function regulator' }\end{array}$ & $\begin{array}{l}\text { 'extracellular region' and } \\
\text { 'extracellular space' }\end{array}$ \\
\hline Sky-blue & 72 & 1-2 WAF & $\begin{array}{l}\text { 'carbohydrate metabolic } \\
\text { process', 'cellular protein } \\
\text { modification process', } \\
\text { 'response to stress', 'cell } \\
\text { communication', 'signal } \\
\text { transduction', 'metabolic } \\
\text { process', 'catabolic } \\
\text { process', 'signaling', } \\
\text { 'protein modification }\end{array}$ & $\begin{array}{l}\text { 'lipid binding', 'hydrolase } \\
\text { activity, acting on glycosyl } \\
\text { bonds', 'enzyme regulator } \\
\text { activity', and 'molecular } \\
\text { function regulator' }\end{array}$ & 'nucleus' \\
\hline
\end{tabular}

transmembrane transporter activity

encapsulating structure', 'cell periphery', and

'cellular anatomical entity' 


\section{Transcriptome Dynamics in Cherry Flowers}

process', 'macromolecule

modification', 'primary

metabolic process',

'regulation of biological

process', 'regulation of

cellular process', 'response

to stimulus', 'cellular

response to stimulus',

'biological regulation', 'cell

wall organization or

biogenesis', and 'organic

substance metabolic

process'

${ }^{1} \mathrm{WBF}$, weeks before flowering; WAF, weeks after flowering. 


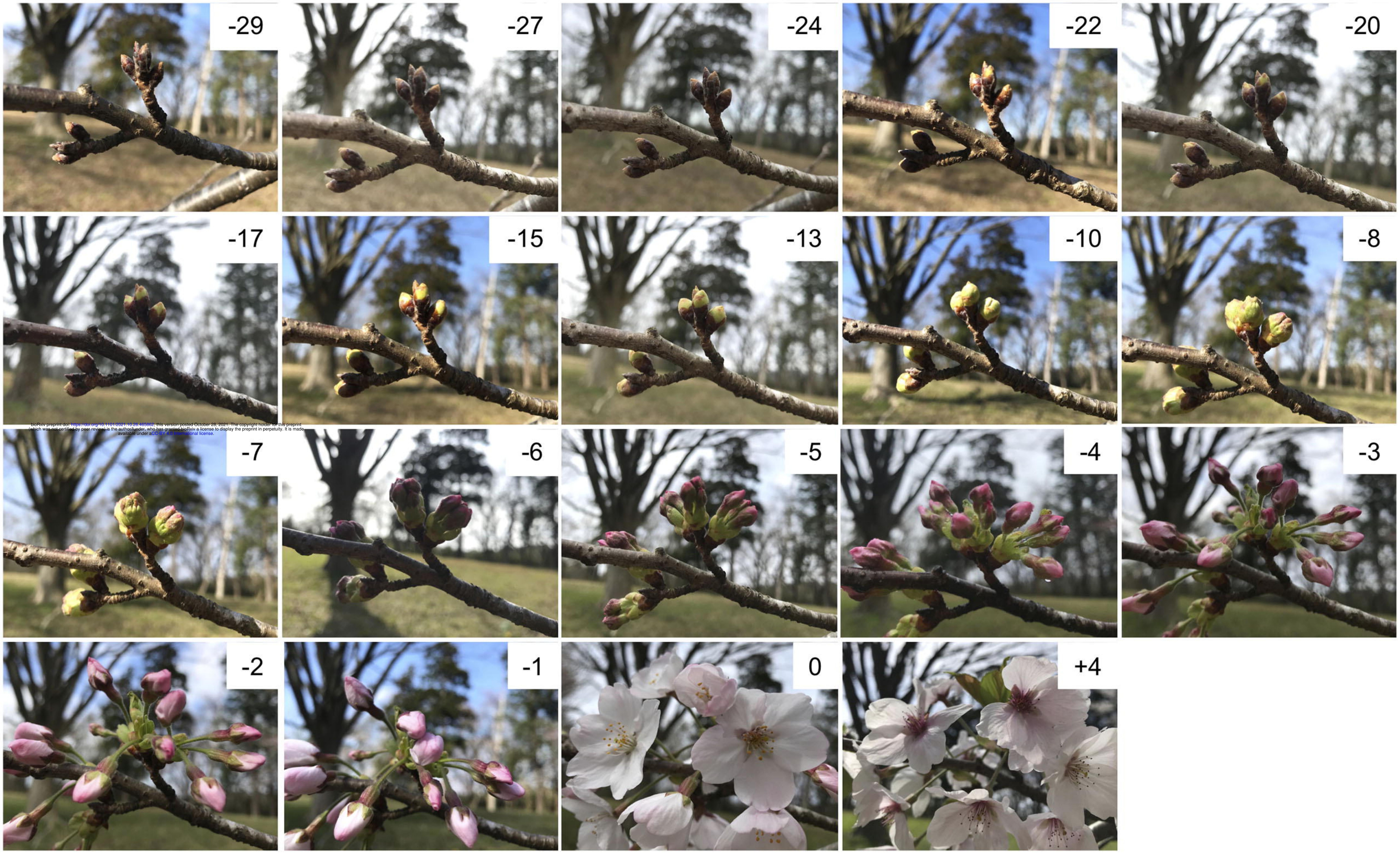




\section{Gene module}

\begin{tabular}{|c|}
\hline \multicolumn{2}{|c|}{ darkred } \\
\hline tan \\
\hline Development \\
\hline
\end{tabular}

pink

royalblue

midnightblue black

\section{black}

skyblue

Biological process

Cell wall organization

Response to stimulus

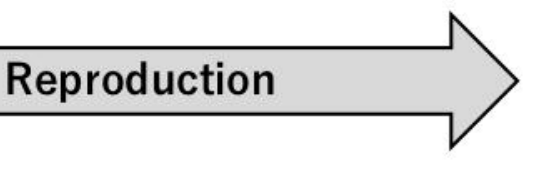

\section{Metabolism}

\begin{tabular}{|c|c|c|}
\hline \multirow{2}{*}{$\begin{array}{l}\text { Transcription } \\
\text { factor genes }\end{array}$} & ERF & NAC \\
\hline & \multicolumn{2}{|c|}{ MYB } \\
\hline
\end{tabular}

\section{Phytohormone-}

related genes
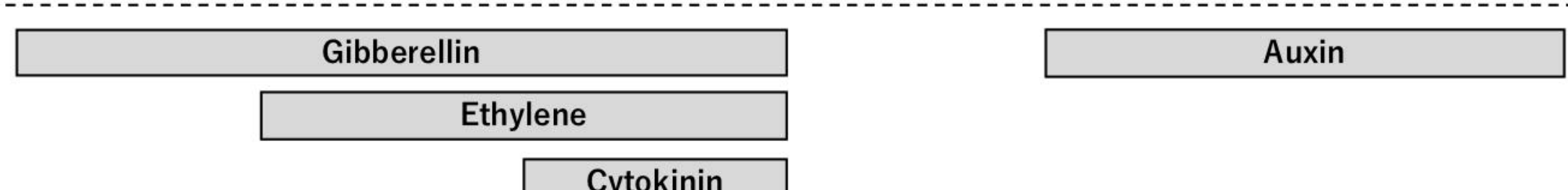

$-$

\section{Transporter and} aquaporin genes

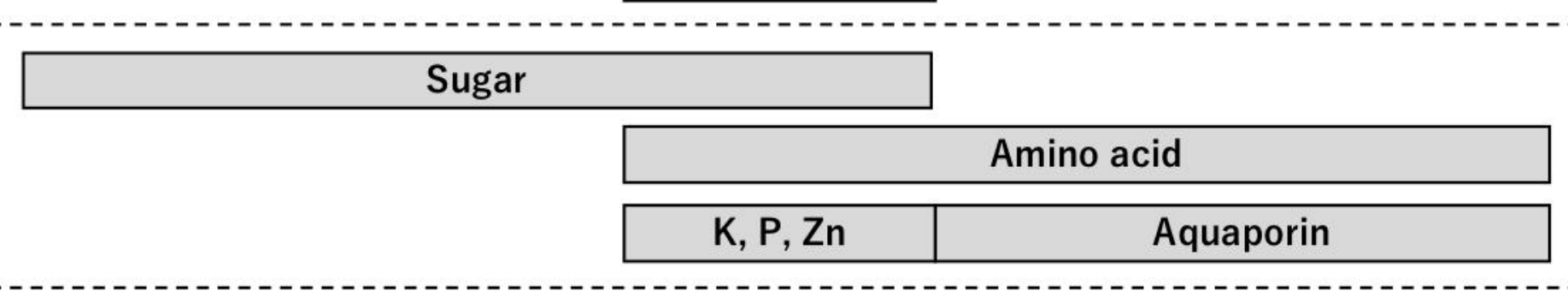

Cell wall-related Fasciclin-like arabinogalactan

